\title{
Glycosylation gap in a group obese subjects
}

\author{
Mohammad Abdul Gafoor Al kataan \\ Department of Clinical laboratory sciences / College of Pharmacy, University of Mosul
}

$\frac{\text { Received }}{21.5 .2012} \quad \frac{\text { Accepted }}{7.10 .2012}$

\begin{abstract}
Back ground: Obesity is major health problem worldwide that increase risk for a wide range of diseases including diabetes mellitus and heart disease. As such, it increasingly important to understand how excess adiposity can perturb normal metabolic functions specially for glucose and lipid homeostasis.
\end{abstract}

Objectives: The study design to evaluate the effects of obesity on the glycosylation process and determine the effects of increase age and BMI on measured parameters.

Materials and Methods: This study was conducted during the period from October 2010 to September 2011 in the department of Clinical Pharmacy under approval of scientific and ethics committee. One hundred individuals were included in this work divided into 2 groups. The first group included fifty apparently healthy individuals (30 males and 20 females) with BMI $(21 \pm 3.1$ $\mathrm{Kg} / \mathrm{m} 2$ ). The second group included fifty individuals (30 males and 20 females) with BMI $(28 . \pm 1.3 \mathrm{Kg} / \mathrm{m} 2)$ whose defined as obese.

Results: The study demonstrated a significant elevation in serum glucose, mean blood glucose, serum fructosamin, measured and predicted $\mathrm{HbAlc}$ in obese individuals as compared with those of control individuals. Glycosylation gap showed a significant elevation in obese subjects when compared to control individual that mean significant elevation in intracellular glycosylation process. Regarding the relation between age and measured parameters, the study showed no significant correlation between age and measured parameters in the control group, while in obese group there were a significant correlation $(r=0.03)$ between ages and predicted $\mathrm{HbAlc}$ and BMI $(\mathrm{p} \leq 0.05)$. Regarding the relation between BMI and measured parameters, the study showed significant correlation between measured parameters and BMI in obese individuals, while in control group only serum glucose and MBG were correlated to BMI $(r=0.01)$ at $(p \leq$ $0.05)$.

Conclusion: obese subjects shows significant increase in glycosylation gap, so there is a significant intracellular glycosylation process that was related to many diseases process and their complication.

Keywords: Glcosylation gap, Obesity, HbA1c, Fructosamin.

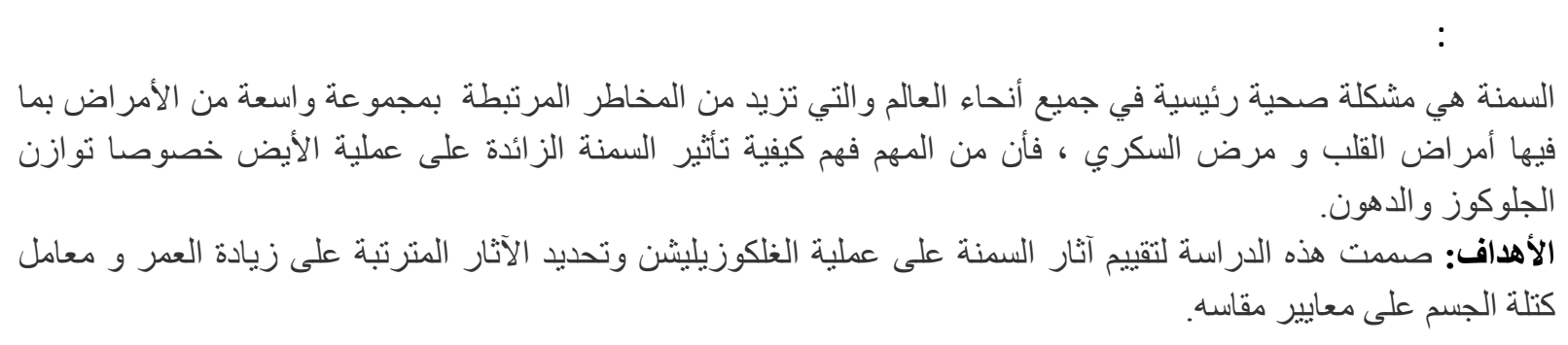




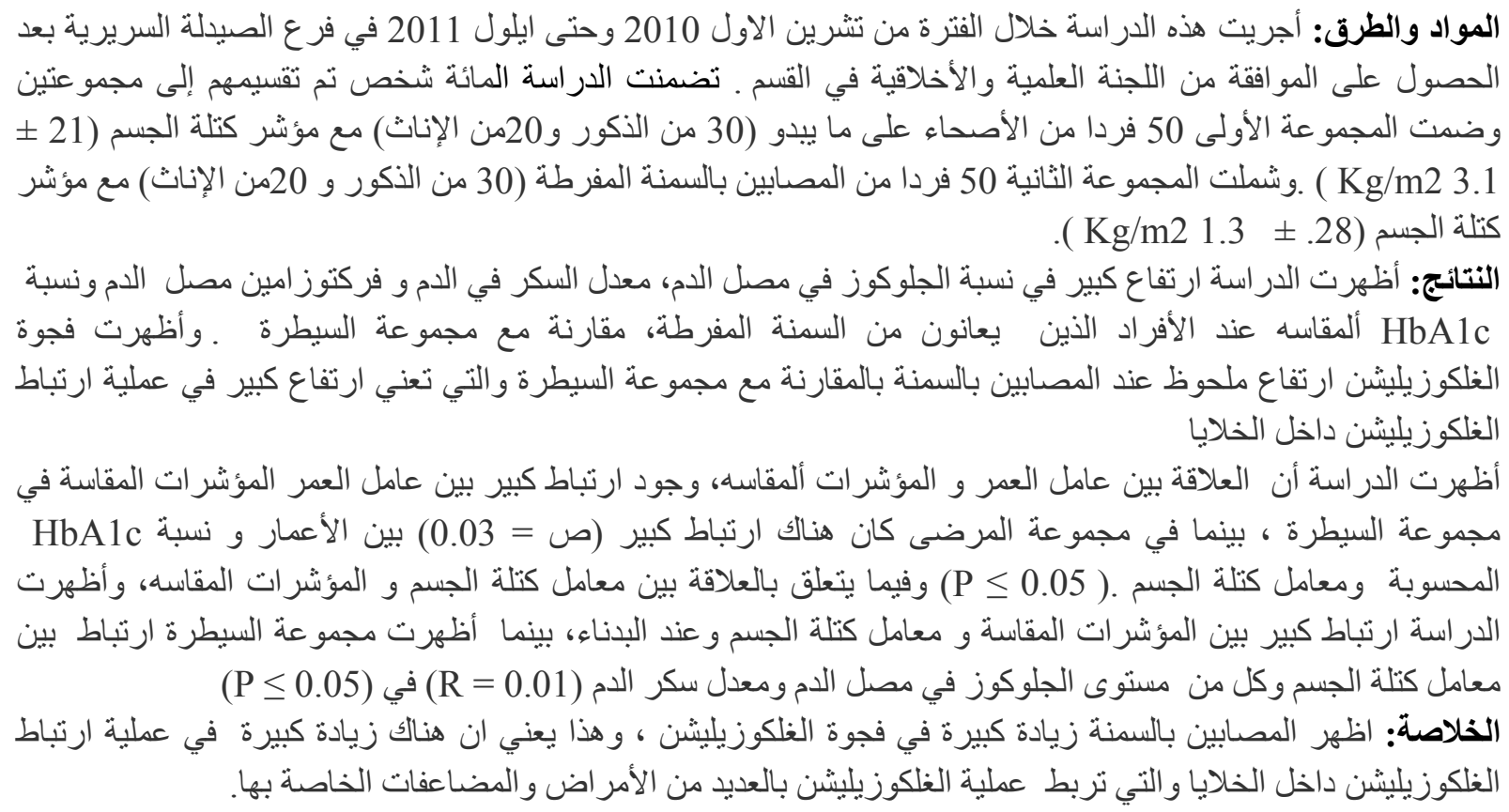

O besity is major health problem worldwide that increase risk for a wide range of diseases including diabetes mellitus and heart disease. As such, it increasingly important to understand how excess adiposity can perturb normal metabolic functions specially for glucose and lipid homeostasis ${ }^{1}$. Glycosylation is a nonenzymatic process in which proteins react with reducing sugar molecules causing impair of their function and change of their characteristics ${ }^{2}$. Glycosylation usually occurs in diabetes, aging and many other diseases where accumulation of glycosylation end products involve in pathogenesis of these diseases and their complications ${ }^{3}$.

Glycated HbAlc result from nonenzymatic - concentration - dependent covalent bonding of glucose to $\mathrm{Hb}$ within the erythrocytes, thereby $\mathrm{HbAlc}$ is a good indicator for glycemic control over long period(2-3months) and also its good
${ }_{8}$ indicator for intracellular glycation process ${ }^{4-}$

The extracellular glycation process also can be evaluated using serum fructosamin, a glycated end product of serum protein ${ }^{4}$. Fructosamin is a measure of average glycemic control over a shorter period (2-3 weeks) and its plasma concentration is much more stable than that of glucose itself and much more easier to measure than true mean blood glucose (MBG), which requires contagious blood glucose monitoring ${ }^{5-10}$.

Glycosylation gap (GG) defined as the value that results from subtraction of direct measured $\mathrm{HbA} 1 \mathrm{c}$ value minus the predicted $\mathrm{HbA1c}$ value obtained from equation using another indicator of glycemic control, fructosamin $(\mathrm{FA})^{6}$. GG used as clinical research tool for evaluating physiological sources of variation that affecting glycemic control and it can also be used as a tool to define the direction of glycosylation process $^{5-10}$. 
In the present work GG is considered as a corner stone of this study to evaluate the effects of obesity on the glycosylation process.

\section{Subjects and Methods}

This study was conducted during the period from October 2010 to September 2011 in the department of Clinical Pharmacy under approval of scientific and ethics committee.

One hundred individuals were included in this work divided into 2 groups. The first group included fifty apparently healthy individuals $(30$ males and 20 females) with BMI $(21 \pm 3.1 \mathrm{Kg} / \mathrm{m} 2)$. The second group included fifty individuals (30 males and 20 females) with BMI $(28 . \pm 1.3 \mathrm{Kg} / \mathrm{m} 2)$ which are defined as obese $^{11}$.

Serum fasting glucose was assayed by glucose oxidase/peroxides colorimetric method12, FA by NBT-spectrophotometric method $^{13}$ and $\mathrm{HbA1c} \%$ measured by Chromatographic-spectrophotometric method14, while mean blood glucose (MBG) predicted $\mathrm{HbAlc}$ and Glycosylation gap were calculated using equations ${ }^{9,15}$. $\mathrm{MBG}=1.76 \times(\mathrm{HbA} 1 \mathrm{c})-3.67 \mathrm{mmol} / \mathrm{L}$ $\mathrm{P}-\mathrm{HbA} 1 \mathrm{c}=0.017 \times \mathrm{FA}+1.61$ $\mathrm{GG}=\mathrm{M}-\mathrm{HbA1} \mathrm{c}-\mathrm{P}-\mathrm{HbA} 1 \mathrm{c}$

Data are presented as mean $\pm \mathrm{SD}, 2$ sample t-test was used to compare between measured parameters in test group and control group. The relationship between age or BMI and the measured parameters were determined by Pearson correlation.

\section{Result}

The study demonstrated a significant elevation in serum glucose, mean blood glucose, serum fructosamin, measured and predicted $\mathrm{HbA} 1 \mathrm{c}$ in obese individuals as compared with those of control individuals Table. 1

Table1. Biochemical parameters in obese group and controls.

\begin{tabular}{|c|c|c|}
\hline Parameters & $\begin{array}{c}\text { Control group } \\
\mathrm{N}=50\end{array}$ & $\begin{array}{c}\text { Obese group } \\
\mathrm{N}=50\end{array}$ \\
\hline Glycosylation gap & $-0.05 \pm 0.23$ & $1.07 \pm 0.31^{* * *}$ \\
\hline Measured HbA1C\% & $5.53 \pm 0.4$ & $6.86 \pm 0.43^{* *}$ \\
\hline Predicted HbA1C\% & $5.45 \pm 0.28$ & $5.87 \pm 0.17^{* * *}$ \\
\hline Mean blood glucose & $111 \pm 13.5$ & $151.3 \pm 13.8^{* * *}$ \\
\hline Fructosamin $(\mu \mathrm{mol} / \mathrm{L})$ & $227.2 \pm 17.4$ & $248.12 \pm 8.16^{* *}$ \\
\hline Serum glucose $(\mathrm{mmol} / \mathrm{L})$ & $81.9 \pm 15.2$ & $96.08 \pm 6.9^{* *}$ \\
$*$ & & \\
\hline $\boldsymbol{p}<\boldsymbol{0 . 0 5}, * *=p<0.01, * * *=p<\boldsymbol{0 . 0 0 1}$ & &
\end{tabular}


Glycosylation gap showed a significant elevation in obese subjects when compared to control individuals that mean significant elevation in intracellular glycosylation process.

Regarding the relation between age and measured parameters, the study showed no significant correlation between age and measured parameters in the control group ,while in obese group there were a significant correlation( $\mathrm{r}=0.03$ ) between ages and predicted $\mathrm{HbAlc}$ and $\operatorname{BMI}(\mathrm{p} \leq$ $0.05)$.

egarding the relation between BMI and measured parameters, the study showed significant correlation between serum glucose, mean blood glucose, serum fructosamin, measured and predicted $\mathrm{HbA} 1 \mathrm{c}$ and GG with BMI in obese individuals.

While in control group only serum glucose and MBG shows significant correlation to BMI $(r=0.01)$ at $(p \leq 0.05)$.

\section{Discussion}

The study demonstrated a significant elevation in serum glucose and MBG in obese subjects as compared to controls and this may be related to an increase in insulin resistance that in turn associated with intravascular hyperglycemia and hypertriglyceridemia that associated with obesity and agree with results described by Ruderman et al, Resnick and Boden et al ${ }^{16-}$ 18 .

Obesity Also associated with a significant reduction in the intracellular $\mathrm{Mg} \backslash$ $\mathrm{Ca}$ ratio that interfere with normal insulin secretion and activity ${ }^{19,20}$. Moreover, low intracellular $\mathrm{Mg}$ concentration will lead to increase adrenergic activity in obese subjects that will lead to increase in gluconeogenesis and glycogenolysis ${ }^{16}$.

The significant elevation in serum fructosamin level in obese subjects can be related to sustained hyperglycemia and this result come in accordance with results obtained by Woo et al and Ardawi et al who describe the influence of obesity on plasma fructosamine concentration ${ }^{21,22}$.

The high HbAlc value in obese individual can also related to sustained hyperglycemia that occur due to impaired glucose metabolism and this agree with results obtained by Power et $\mathrm{al}^{11}$. The substantial increase in GG in obese subjects may be related to significant elevation of measured $\mathrm{HbAlc}$ value over the predicted $\mathrm{HbA1c}$ value that obtained from equation using serum fructosamin.

The study also revealed that with increasing age, predicted $\mathrm{HbAlc}$ will increase in obese subjects and this in consistence with results obtained by Martins et $\mathrm{al}^{23}$ and this may be due to the increase in the extracellular- intravascular glycation. BMI showed significant correlation with measured parameters in obese group and this is in consistence with results obtained by Power et $\mathrm{al}^{11}$.

In conclusion obese subjects shows significant increase in glycosylation gap, so there is a significant intracellular glycosylation process which may be the underlying cause of many diseases process and their complication.

Further studies are required to investigate the exact role of GG in clinical diagnosis. 


\section{References}

1. Hummasit S, Hotamisligil G. Endoplasmic reticulum stress and inflammation in obesity and diabetes. Circulation research 2010;107:579-591.

2. Smart LM, Howie AF, Young RJ, et al. Comparison of fructosamine with glycated hemoglobin and plasma proteins as measures of glycemic control. Diabetes Care 1988;11:433436.

3. Nathan DM, Singer DE, Hurxthal K, et al. The clinical information value of the glycosylated hemoglobin assay. N Engl J Med 1984;310:341-346.

4. Nayak A, Holland M, Nevill A, et al. Evidence for consistency of glycation gap in diabetes. Diabetic Care 2011;34(8):1712-1716.

5. Cohen R, Holmes $\mathrm{Y}$, Chenier $\mathrm{T}$, et al. Evidence for Independent Heritability of the Glycation Gap (Glycosylation Gap) Fraction of HbAlc in Non diabetic Twins Diabetes Care 2006; 29(8): 1739-1743.

6. Lachin J, Genath S, Nathan D, et al. The hemoglobin index is not an independent predictor of the risk of micro vascular complications in diabetes control and complications. Diabetes 2007;56:1913-1922.

7.Robert M, Holmes R, Thomas $\mathrm{C}$, et al. Discordance between HbAlc and Fructosamin evidence for a glycosylation gap and its relation to diabetic nephropathy. Diabetes Care 2003;26(1):163-167.

8. Baker R, O Connor P, Metcalf A, et al. Clinical usefulness of estimation of fructosamin concentration as screening test for diabetes mellitus. $\mathrm{Br}$ Med $\mathrm{J}$ 1983;288:863-867.

9. Baker R, Johnson N, Scott J. Serum fructosamin concentration in patients with type II diabetes mellitus during changes in management. $\mathrm{Br}$ Med $\mathrm{J}$ 1984;287:1484-1486.

10. Lester E. The clinical value of glycated hemoglobin and glycated plasma proteins. Ann Clin Biochem 1989;26:213-219.

11. Power C, Thomas C. Changes in BMI, duration of overweight and obesity, and glucose metabolism: 45 years of follow up of a birth Cohort. Diabetes Care 2011;34(9):1986-1991.

12. Lotta JA, Turner K . Evaluation of trinder's glucose oxidase method for measuring glucose in serum and urine. Clin Chem 1975;21:1754-1760.

13. Baker R, Patricia M, Roger N. et al. Use of protein-base slandered in automated colorimetric determination of fructosamine in serum Clin.Chem. 1985;31:1550-1554.

14. Bisse E, Abraham EC. New less temperature sensitive micro chromatographic method for the separation and quantitation of glycated hemoglobin using a non-cyanide buffer system. Chromatog 1985;344:81-91.

15. American diabetes association. Use of the estimated average glucose (eAG) in patient care. Updated February 2009.http://profisional .daibetes.org/content/eAGP power point slide.ppt. accessed in Jun 2011.

16. Ruderman N, De Groot, Jameson L J. The metabolic syndrome Endocrinology, 5th edition Elsevier Philadelphia, U.S.A. 2006: 1149-1166. 
17. Resnick L.Cellular $\mathrm{Ca}++$ and $\mathrm{Mg}$ metabolism in the pathphysiology and treatment of hypertension and related metabolic disorders. Am J Med 1992;93: 115-205.

18. Boden G, Jadali F, White J. Effects of fat on insulin-stimulated carbohydrate metabolism in normal men. J ClinInves 1991;88:960-966.

19. Boullin D. The action of extra-cellular Cat-ions on the release of sympathetic transmitter from peripheral nerve. J Physol 1967;189:85-99.

20. Seelng $\mathrm{M}$. Consequences of $\mathrm{Mg}-$ deficiency, enhancement of stress action, preventive and therapeutic implication. J Am Collnutr 1994;13:429-446.

21. Woo J, Cockram C, Chan A. et al. Influence of obesity on plasma fructosamin concentration. Clin Chem 1992;38(11):2190-2192.

22. Ardawi M, Nasrat H, Bahnassy A. Fructosamin in obese normal subjects type 2 Diabetes. Diabet Med1994;11(1):50-56.

23. Martins R, Jones J, Cumming S, et al. Glycated hemoglobin and association risk factors in old adult. Cardiovas Diabetol 2012;(1):11-13. 